\title{
Picasso alquimista: Una lectura de "Las Meninas"
}

\section{Alchemist Picasso: a Reading of "Las Meninas"}

Guadalupe Lucero

Universidad de Buenos Aires, Argentina

guadalucero@yahoo.com.ar

Resumen • Este texto presenta una lectura de la serie Las meninas según Velázquez que Picasso realizó en 1957, articulada en tres momentos: 1) revisión de las interpretaciones clásicas de Las Meninas, que poco después de la aparición de la serie picassiana se reactivan en torno al clásico texto de Michel Foucault que preludia Las palabras y las cosas; 2) presentación de la serie a la luz de una dialéctica de la falsificación y 3 ) análisis del vínculo forma-contenido a partir de la problematización de la noción misma de "variación", buscando algunas resonancias con la lógica musical de la variación. Consideramos que la radicalidad del ejercicio picassiano se encuentra en el centro de lo que se le reprocha: su potencia falsificante.

Palabras clave: Picasso, Meninas, falsificación.

Abstract - The objective of this essay is to reflect on Picasso's Las meninas según res on Las Meninas since Foucault published his essay in Les mots et les choses (1966); secondly, and taking as a starting point Rosalind Krauss' essay on Picasso, The Picasso Papers, we will read the series as a dialectic of fake and falsification, and finally we will analyze the relationship between form and content through the problemposing of musical variation. We would like to point out that what is revolutionary in Picasso's series is indeed their fake power.

Keywords: Picasso, Meninas, Fake. 
Hemos eliminado el mundo verdadero: ¿qué mundo ha quedado?, ¿Acaso el aparente?... ¡No!, ;al eliminar el mundo verdadero hemos eliminado también el aparente!

En 1957 Picasso se retiró a Cannes y pintó los 58 lienzos que componen la serie de Las meninas según Velázquez. No es la primera vez que Picasso versiona una obra, aunque quizás sea ésta la serie más numerosa. Respecto a semejante uso de las imágenes de la tradición, se ha señalado tanto que el reciclaje picassiano de obras maestras del pasado, no constituye sino el índice de su decadencia inventiva (Berger, 1973:117), como también que con esta serie Picasso se colocaba a la altura del genio sevillano (Galassi, 2008: 92). que con esta serie Picasso se colocaba a la altura del genio sevillano (Galassi, 2008: 92).
Nos gustaría situarnos en un punto no exactamente intermedio a éstos, sino casi tangente. Consideramos que la potencia farsante de la intervención picasiana es lo que justamente permite una lectura novedosa de la pintura, a partir de la transvaloración de aquella "teología de la pintura" que Las Meninas representaría. La alquimia picassiana habría ajustado la equivalencia de valor entre los espejos de colores y el oro, ya que una lectura profunda de la teología de la pintura, no podía ser sino una ontología de lo falso.

Afrontar una lectura de la serie que alberga el Museo Picasso de Barcelona, nos enfrenta con al menos tres cuestiones. En primer lugar, el peso histórico de Velázquez y particularmente de Las Meninas. No podemos dejar de reseñar brevemente las lecturas del cuadro para la vez comprender la opción picassiana. En segundo lugar, la necesidad de situar a Picasso respecto de su propia elección. ¿Qué camino seguir para partir del Picasso vanguardista y llegar a este Picasso maduro, que recupera la tradición como tema pictórico? A estos dos grandes escollos se nos suma un tercero, quizás más ligero, y por eso quizás más importante: ¿Qué es lo que hace exactamente Picasso con Velázquez y con el aparente "problema" de Las meninas? ¿Cómo leer el procedimiento de la serie y la variación?

\section{BAJO EL PESO DE VELÁZQUEZ}

Al lector seguramente le resulte redundante una nueva descripción de la obra de Velázquez en cuestión. Sabemos que hay un espejo, que el pintor se ha representado a sí mismo pintando un lienzo del que vemos el reverso, que en el espejo probablemente se reflejen los reyes, que el resto de los personajes pertenecen al entorno de la familia real y que en el centro está representada la infanta Margarita. La profusa bibliografía en torno al cuadro, nos señala al menos dos aspectos que a menudo se reiteran y se reelaboran desde distintos puntos de vista: aquel que señala en el cuadro una alegoría de la representación pictórica y aquel que subraya su modernidad en el carácter fotográfico del tratamiento del tema.

Existe un texto central en torno a la lectura filosófica contemporánea de Las Meninas de Velázquez; el texto de Michel Foucault que abre Las palabras y las cosas. La lectura de Foucault es conocida; para él el cuadro de Velázquez constituye un ejemplo elocuente de lo que él llama la episteme clásica y que se opone a lo que en el segundo capítulo de dicho libro llama la episteme renacentista. Para Foucault, en Las meninas se hace evidente que la continuidad entre las palabras y las cosas de aquel un mundo pre-moderno atravesado por la lógica de las semejanzas, se ha roto definitivamente. El juego de miradas que el cuadro habilita muestra la estructura misma de la representación a partir del siglo XVI. Será necesario un sujeto en un punto vacío, intercambiable, que funcione como garante del vínculo artificial y convencional entre el mundo y su representación. Esta intercambiabilidad es posible gracias al rol central del espejo que permite que el espectador del cuadro se sitúe a la vez en el lugar del modelo, al caer bajo la mirada del pintor, y al mismo tiempo en el lugar de los soberanos reflejados en el espejo. Objeto de representación y sujeto de la representación soberana. El nudo del texto foucaultiano, parece estar para muchos autores en el final, allí donde se señala que en Las meninas "la representación puede darse como pura representación". La función del espejo sería justamente la de hacer salir la pintura del cuadro en dirección al espectador, hacer jugar al espectador, ubicado en el espacio del sujeto cualquiera, el rol del soberano reflejado, y a la vez distribuir un juego de miradas que hace bascular el problema de la representación desde el objeto representado hacia el sujeto que la efectúa.

Otro artículo que se sorprende con el espejo es "Las meninas y las paradojas de la representación pictórica" de John Searle, donde se analiza el cuadro desde el punto de vista de las aparentes contradicciones en él implicadas. Las paradojas son el resultado de la violación de lo que Searle llama "representación pictórica clásica". Lo que caracteriza a las representaciones visuales en la "representación pictórica clásica" es el hecho de que necesariamente hay un punto de vista que determina el aspecto de la imagen que se organiza del siguiente modo:

El artista (o la cámara) ve un objeto o una escena desde un punto de vista, que debe ser exterior a lo visto, puesto que no podemos ver el ojo con que estamos mirando. El artista a exterior a lo visto, pusto que no pode us ver el ojo con que pula continuación produce sobre una superficie plana un objeto tal que, cuando el espectador se que tuvo el artista (Searle, 1980: 481).

Para Searle aquello que desestabiliza esta lógica pictórica es la presencia del espejo, que desencadena una serie de paradojas, brevemente que el punto de vista del artista está ocupado por la imagen de los reyes reflejada en el espejo, es decir el punto de vista del artista está ocupado por el modelo, y el artista es por su parte el objeto de la representación. Es curioso que Searle equipare el artista a la cámara. La paradoja funciona siempre y cuando consideremos que la escena representada puede haber sido vista por el pintor. Es decir, debería ser posible "sacar la foto" de la escena. De algún modo, encontramos eco aquí de aquella lectura que veía en la escena de Las Meninas el motivo de una instantánea, y de allí la modernidad casi impresionista de Velázquez que Saxl reafirma en su comentario "Velázquez y Felipe IV" (1989: 287).

Velázquez y Felipe IV" (1989: 287).
Snyder y Cohen dedican un detallado artículo a deshacer estas paradojas cuyo origen es el espejo. Para los autores, el error de Searle y de Foucault es colocar el punto de fuga de la perspectiva en el espejo, y a partir de allí errar respecto del lugar del espectador y el reflejo de los reyes. Un simple estudio de la geometría exigida por la representación clásica literalmente destruiría el análisis de ambos filósofos. El espejo no refleja ni a los reyes fuera del cuadro, ni es ambiguo respecto de nuestra propia posibilidad de ser atrapados en el reflejo especular, ya que el reflejo del espejo es simplemente el de la tela que no vemos y que el pintor pinta. Así el problema del espejo en Las meninas quedaría simplemente disuelto y las paradojas que desencadena solo serían fruto de un mal sueño escolástico. 
Sin embargo el espejo nunca juega un rol inocente; es depositario de los mas grandes males a la hora buscar una representación del mundo. El rol del espejo en toda una historia de la filosofía es justamente el de engañarnos respecto a lo que refleja y a su realidad. Su carácter paradójico se acentúa aquí si lo observamos en relación con el rol de las ventanas. Sabemos que en el cuadro de Velázquez las ventanas de la derecha aparecen cerradas esas otras ventanas que serían los cuadros, están sumidas en la penumbra, a excepción del espejo que refleja y demarca su propio rectángulo de luz. Es como si la cuestión del espejo se nos mostrara como en contrapunto tanto de la función de las ventanas como de los otros cuadros. Este punto es el que ve Foucault, cuando le adjudica una centralidad particular. Pero es también sobre este punto que Searle analiza sus paradojas: justamente el espejo es el que desestabiliza la posibilidad de aquella representación que tenía a la ventana como metáfora esencial.

A pesar de la lectura errónea de la función del espejo en la composición, vemos que tanto en el caso de Foucault como en el de Searle, se hace patente la pervivencia de las clásicas lecturas del cuadro: la referencia a la instantánea fotográfica y la relación con cierta alegoría de la representación pictórica. Esta última nos interesa particularmente, La expresión resulta fundamental para comprender el gesto picassiano. No una mera "apología” de la pintura, sino una "teología”. La pintura debería convertirse o bien en el escenario privilegiado de una lógica divina, o bien ella misma manifestación y ejemplo de la creación absoluta. Si esto es así, las consecuencias llegan un poco más allá de la mera exposición de la representación como pura representación. La pintura retomaría aquí una función que había estado relegada a la metafísica: aquélla de develar el fundamento o la verdad última. Encontramos en los programas vanguardistas ecos de semejante pretensión, y es justamente en ese sentido que la vanguardia ha sido pensada en continuidad con la modernidad, antes que en ruptura con ella. Quizás sea contra estas pretensiones que e exponente más influyente de la pintura del siglo XX haya decidido arrojarse al mundo de las "versiones".

\section{PICASSO FALSIFICADOR}

Si hay alguien a quien le gustan las paradojas es Orson Welles. Pero no le gustan en tanto que trampas para el pensamiento, sino que en tanto desafíos que exigen y llevan hacia un límite nuestra capacidad de análisis racional. Le interesan como umbral que, una vez traspuesto, vuelve indiscernible lo verdadero de lo falso, o más bien, vuelve inútil la diferencia. En ningún otro film ha llevado esta potencia a tal extremo como en $F$ for Fake. En ella se nos relata la historia de un falsificador, su biógrafo, su marchante, su nieta amante de Picasso entre otros personajes, cuyo núcleo central es forzar la lógica de la ficción falsificante hasta disolver la distinción entre originales y falsificaciones. Es de algún modo una gran alegoría de la pintura: aquel espacio donde justamente la distinción entre originales y copias resulta más exagerada en tanto más indiscernible.

Sabemos que ya Platón condenaba la pintura justamente por su carácter desviado respecto de una lógica que repartiría el mundo bajo las categorías de lo verdadero y lo falso. La pintura construye imágenes cuyo carácter fundamental es escapar a la égida de la Idea. Evidentemente no se trata simplemente de un problema de "degradación” ontológica. En el famoso ejemplo de la cama, la cama que hace el carpintero también tiene menor peso ontológico que la Idea. Pero la copia del pintor no es mero efecto de un movimiento de adelgazamiento ontológico, sino que se trata más bien de una "excepción" ontológica. Las imágenes pictóricas no tienen con las cosas sensibles la misma relación que éstas con la Idea. Entre las cosas y la Idea existe una relación de dependencia, de jerarquía y de semejanza estructural. La Idea es lo que sustenta el "proyecto" que se seguirá a la hora de construir la cama. Sin embargo, entre la imagen pictórica y las cosas del mundo esa relación es una mera excusa: la imagen no necesariamente se construye siguiendo la esencia de la cosa, la imagen tampoco está en relación jerárquica respecto de la cosa. Justamente porque de lo que se ocupa la imagen es de su modo de "aparecer" y no de su modo de "ser".

Steinberg, en su análisis de Las Meninas se encuentra próximo al diagnóstico de Platón. Nos dice que el lienzo nos presenta tres modalidades de lo visible: la realidad, la ilusión y la réplica. Los reyes, su reflejo en el espejo y el cuadro. Sólo que aquí "[1]a realidad, la ilusión y la réplica que lleva a cabo el arte se mueven en una circulación incesante”. En otras palabras, el peligro que preocupa a Platón en el libro X de República se ve aquí confirmado. Si el cuadro es una "teología de la pintura" es porque la pintura disuelve esas distinciones, las pone en circulación. No es casual que las últimas palabras de Steinberg refieran a la metáfora especular: el espejo puesto frente a otro espejo no puede sino desarmar los puntos fijos. No es tanto un espejo de la conciencia, la conciencia no confunde estos planos, es más bien lo que libera de las ataduras de la representación a lo real para darlo como mera representación que, así liberada, sólo puede volverse inasignable. El espejo era también el ejemplo que Platón utiliza para explicar el modo de hacer del pintor.

Cómo interviene aquí, entonces, Picasso? Rosalind Krauss le dedica un hermoso libro. Los papeles de Picasso, en el que no es justamente condescendiente con él. Krauss se instala desde el comienzo en el nudo del problema picassiano que nos permitirá abordar Las Meninas. En el capítulo introductorio analiza un problema central de la vanguardia: su relación con la falsificación. A través de la lectura paralela de la novela de Gide Los monederos falsos y la Filosofía de la nueva música de Adorno, nos muestra la estrecha relación que une la práctica vanguardista con el problema del fraude. Por un lado, a partir del corte entre representación y referente operado por los movimientos artísticos de principios de siglo, la relación con lo verdadero se desplaza, se vuelve signo. Este vaciarse de contenido puede interpretarse como el resultado de una relación más profunda con el control de los medios y su interiorización, pero también implica el peligro de verse sometida al intercambio generalizado. Desnudez simbólica a la que la vanguardia llega y que corre el riesgo, justamente por su vacuidad y transparencia, de ser reconvertida en oro, de ser vestida de nuevo para circular alegremente en el mundo de las mercancías, la vanguardia como fraude, como mero simulacro vanguardista.

El problema del fraude se cristaliza en el "caso Picasso", particularmente en la exposición de 1919 en la que el pintor malagueño decide exponer en conjunto cuadros cubistas con dibujos y cuadros neoclásicos. Picasso estaría aquí simplemente traicionando el proyecto modernista. Su procedimiento se acerca a aquello que Adorno llamó "pastiche" para referirse a Stravinsky: hacer uso de un contenido agotado, aquel que la historia del arte brinda, y convertir ese recurso a la cita y a lo ya elaborado en el contenido mismo del arte (Krauss, 1999: 19-33). Krauss detona su juicio sobre Picasso hacia el final de esta introducción:

El precio de esta "inflación" ha sido olvidar que el oro semiótico hallado al convertir el papel de periódico en el signo para "luz" o "aire" difiere sustancialmente de la costosa extracción del arte del pasado al servicio de las leyes del pastiche, según las cuales la moneda 
lingüística de la pureza vuelve a acuñarse como la bonanza económica de la falsificación estética. Y así también puede percibirse una bienvenida nota de depreciación en este "céntimo para Picasso" que no difiere del algo condescendiente "penique para el pobre tipo", de Eliot. El esplendor y la miseria, podríamos decir, del artista moderno (32).

No salvaremos a Picasso del juicio de falsificador a través de una condescendencia posmoderna gracias a la cual el museo imaginario finalmente está democráticamente disponible. Si algún tipo de justificación nos gustaría dar para el "fraude picassiano" es la que hace justicia a la lógica del falsificador. También Welles en el film mencionado hace referencia a este poder alquímico de Picasso: todo lo convierte en oro. Pero para darle un signo opuesto.

En La imagen-tiempo. Estudios sobre cine 2, Deleuze dedica un largo capítulo a lo que llama las "potencias de lo falso", cuyo protagonista fundamental es Orson Welles. Si una reflexión respecto a la crisis de la verdad tiene lugar en este tomo dedicado al pensamiento cinematográfico del tiempo, es porque la forma misma del tiempo es la que tradicionalmente pone en crisis la noción de verdad. Se trata de un nuevo estatuto de la narración cinematográfica, que, en lugar de ser verídica, se hace esencialmente falsificante. Esto no equivale a un relativismo de la verdad, según el cual cada cual tiene su verdad. Si así fuera, la noción de lo verdadero no sufriría una verdadera crisis, ya que dicho relativismo sólo hace referencia a una variabilidad de contenido que deja intacta la forma de lo verdadero. Se trata más bien de lo que Deleuze llama las potencias de lo falso que reemplazan a la forma de lo verdadero (1986, 185-198). Volveremos sobre este punto.

La falsificación picassiana implica, antes que una traición a la vanguardia, o la simple coartada de un pintor al que se le han acabado los temas, un profundo trabajo de extracción gestual que no obedece a las leyes del signo con su arbitrariedad, vacuidad y posibilidad de movimiento. Lo que se extrae no son ni los personajes, ni una forma vacía, ni un mismo problema. De acuerdo con un diálogo referido por Sabartés, Picasso habría dicho respecto de Las meninas:

Si uno se pusiera a copiar Las meninas, de toda buena fe, pongamos por caso, al llegar a cierto punto y si el que copiase fuese yo, me diría: ¿qué tal poner a ésa un poquitín más a la derecha 0 a la izquierda? (cit. en Rafart, 1999: 40).

Seguir de cerca a los personajes para hacerlos mutar y volverlos irreconocibles, tirar del punto de fuga de la composición para generar pequeños temblores en la estructura del cuadro, construir a su alrededor un nuevo problema que viene a desplazar a su problema más propio. Se trata de una apretada captura de signos fijados antes que liberados, que son transvalorados antes que purificados. La "obra maestra del arte universal” se descuartiza y se expone en una serie de lienzos que no hacen sino cuestionar su unicidad y su carácter acabado.

\section{VARIACIÓN Y SERIE}

Krauss señala que Picasso transita en el cubismo y el collage la vía moderna qu, al romper la relación entre representación y referente, empuja la pintura hacia un devenir sígnico. Es en este sentido que el retorno a los contenidos neoclásicos implicaría una traición al proyecto esta vía sino que la atraviesa y transvalora sus condiciones de posibilidad. Picasso no se sube a la metáfora (Cf. Derrida, 1989). Conjura su propio peligro: el devenir mero signo vacío. El retorno es más bien una operación de transvaloración en el sentido que Nietzsche daba a este término. Transvalorar no era "invertir" los valores, camino que parece seguir el proyecto de la vanguardia, sino extraer nuevos valores.

El espejo, elemento central en todas las interpretaciones de Las meninas, no es simplemente abandonado por Picasso. Atraviesa una serie de transformaciones, que implican una gravitación amplia de Velázquez en su obra. Cuadro o ventana, el espejo deja de tener un privilegio particular en la composición de Las Meninas. Robert Lubar muestra como la estructura formal de Las Meninas y el lugar del espejo aparecen a menudo en lienzos del periodo pos-cubista, particularmente en El taller (1927-1928) y El pintor y la modelo (1928). Allí el espejo aparece en posición similar a aquella del cuadro velazquiano, pero opacado, pintado de gris. El espejo pierde toda su función reflejante para convertirse más bien en un agujero negro que absorbe sin reflejar. Lejos está también de cumplir el rol de una ventana, ventanas que en este periodo aparecen por doquier y que siempre se abren hacia un exterior que contrasta con la interioridad del taller o de los bodegones. Respecto del segundo lienzo mencionado, Lubar indica que:

La concepción del lienzo como objeto que es posible estirar y clavar en un soporte de madera constituye una manera de lanzar un reto a la relación entre modelo y la naturaleza y el mundo de las apariencias. La venerable idea de la pintura concebida como una ventana abierta a mundo sufre una inversión, y la representación aparece definida como una serie de apuestas formales y mecanismos conceptuales. El taller y El pintor y la modelo son, por consiguiente, alegorías de la representación (Lubar, 2008: 77).

El análisis picassiano implica una lectura más profunda del problema de la representación, más pictórica quizás, una lectura arrepresentativa del cuadro y un análisis del vínculo forma-contenido que se acerca más a aquella mentalidad pre-clásica que Foucault analiza en el segundo capítulo de Las palabras y las cosas, que al clasicismo que Velázquez vendría a inaugurar. Ni espejo ni ventana, la pintura no es ya con relación a otra cosa sino sólo en función de sí misma. Pero Picasso también se ha desecho, escandalosamente o no, del problema de la "purificación" de la pintura como lenguaje. La cuestión no es ya la relación con el mundo y la figuración. Pero si ya no es un problema ¿qué necesidad hay de evitarlo? La frase de Nietzsche que nos sirve de epígrafe nos habla de este problema: no invertir, La frase de Nietzsche que nos sirve de epígrafe nos habla de este problema: no invertir,
sino pasar. Y en el caso de la pintura, no se trata de negarle a la pintura todo contenido figurativo e incluso tradicional, sino de hacer de ese contenido otra cosa, por ejemplo un movimiento, un gesto.

Una metáfora reaparece a menudo respecto del análisis de la serie de Las meninas de Velázquez de Picasso: la variación musical. Cuando en sucesivas ocasiones se apela a la noción de variación musical, se hace referencia a la posibilidad de operar transformaciones sobre un tema base. Si analizamos unas variaciones musicales clásicas lo que nos encontramos es una presentación del tema, y luego reescrituras del tema modificando el modo, la velocidad, la textura, etc. Ahora bien, hay aquí un problema esencial, y es que la variación en música pertenece de cabo a rabo a un modo de representación y de composición musical que es más cercano a la época de Velázquez que a la de Picasso. Es decir, la variación es una forma musical que pertenece al periodo clásico y romántico, pero que pierde su sentido esencial en la vanguardia vienesa. Evidentemente, a la hora de analizar as distintas operaciones que se realizan sobre una serie dodecafónica, podemos hablar de variaciones, pero ya no se trata en absoluto de un tema con variaciones. Si bien se utilizan 
"variaciones de la serie" (trasposiciones, retrogradaciones, inversiones), esto sucede a nivel de la determinación del material y no de la forma. Con esto queremos indicar que la noción misma de variación si bien permite entender algunas cuestiones de índole formal, no es suficiente para dar cuenta de la especificidad de la variación en el caso de Picasso y en e arte posterior a los '50 en general. La música posterior a los' 50 ha trabajado variaciones, aunque de un modo completamente distinto. La noción de variación, si aún es utilizable, debe ser contemplada desde una perspectiva post-serial, es decir, como la operación que intenta extraer la forma desde un material que ya ha sido sometido a un proceso formal. La forma de expresión y la forma de contenido son trabajadas conjuntamente a través de una operación particular de encastre.

Es necesario aplicar la noción de variación a dos ámbitos diferentes: aquel de la forma del contenido y aquel de la forma de la expresión. Esto es claro en música y es claro desde el dodecafonismo justamente, donde esta noción de "informar el contenido" se hace presente. Cuando Schönberg concibió el dodecafonismo como sistema compositivo, de lo que se trataba ante todo era de controlar el material con una estructura abstracta que evitara el efecto motívico, es decir, el reconocimiento de un tema, tal como sucedía en la música tonal. Sin embargo, se trata de un proceso para informar el material antes de estructurarlo en una forma temporal. Esta distancia entre forma del contenido y forma de la forma, o como indican Deleuze y Guattari, forma de expresión (1988: 90-92), se hace patente en las críticas que sufrió Schönberg luego del desarrollo del dodecafonismo. Se trataba de una forma de contenido totalmente nueva, un tipo de relación entre los elementos utilizados para la composición totalmente nuevo. Pero a la hora de dar una forma expresiva a ese material, se recurría a formas viejas: el Vals, la Sonata...

En el caso de Picasso parece que nos encontráramos en el lugar inverso al de Schönberg: un contenido viejo para una pluralidad novedosa de formas de expresión. El viejo reproche de Berger: Picasso no tiene temas propios. Reencontramos gestos de formas ya elaboradas minuciosamente por Picasso, que son operadas desde dentro por un material antiguo. Pero quizás Las meninas no sean tanto el "contenido" de la serie picassiana como su forma. O más bien, no se reduce a una relación abstracta entre forma y contenido o temas, sino a un encuentro particular entre un contenido pictórico ya elaborado con una composición particularmente celebrada. Picasso pone en obra allí toda una serie de elaboraciones pictóricas anteriores, y los personajes del cuadro velazquiano son más bien el espacio donde el mundo picassiano viene a reencontrarse. El artista utiliza entonces un "contenido" informado, altamente elaborado y que responde a largos años de experimentación pictórica, y una estructura formal que es sometida a un proceso doble: la traducción y la serialización, operaciones ambas que proceden del tratamiento mismo del material pictórico ya elaborado.

La traducción aquí no implica un simple paso de un código a otro. Se trata más bien de una transcodificación; los cambios en el código dado se producen a través de sus márgenes de descodificación. Allí donde los personajes de Velázquez cristalizan un gesto, Picasso hará brotar sus propios gérmenes. Y se trata a su vez de un despliegue de la composición velazquiana en una serie que remite necesariamente a un modo de encuentro con la obra deudor de la experiencia temporal antes que la inmediatez clásica de la experiencia pictórica.

El personaje al que Picasso dedica mayor cantidad de lienzos es el de la Infanta. En el cuadro de Velázquez ocupa el lugar central. Su rostro se encuentra levemente girado pero sus ojos están mirando hacia el frente. Este cruce entre frente y perfil es explotado por Picasso en los estudios sobre la niña, donde reencuentra sus propias elaboraciones del rostro. Es sobre ese rostro, a su vez, sobre el que comenzará a trabajar el problema del color (MP
70440, MP 70441, MP 70442), acentuando las líneas que lo dividen y reencontrando en él líneas inusitadas.

Como siguiendo un procedimiento cinematográfico, Picasso hace primeros planos de ese personaje central, planos medios, también algunos de cuerpo entero. El encuadre es uno de los elementos que Picasso hace variar a lo largo de la serie, y es lo que hace que el espacio comience a sufrir distintas transformaciones, que lo conducen a un aplanamiento hacia el final de la serie que desarma la profundidad a través de la intensificación del rojo en el fondo y de la esquematización de los personajes que se insinúan con planos de color

Algo se está escapando, es lo que todos vemos de inmediato en Las meninas: alguien se va por la puerta de atrás, ese es el punto de fuga de la perspectiva y el punto de fuga que Picasso interpreta literalmente. Hay que empezar por ese margen. El primer lienzo, que toma el conjunto, da algunas claves generales del procedimiento. Velázquez es tan grande que toca el techo, pero solo para guiarnos hacia la diagonal que desemboca en Nieto. Las ventanas abiertas contrastan con las ventanas cerradas de Velázquez. La ventana será un elemento central que toma total protagonismo en la "serie dentro de la serie" de los pichones y también en el cuadro que cierra el conjunto y que a la vez no forma parte del él: el retrato de Jacqueline. El Velázquez desmesuradamente grande de este primer lienzo, reaparecerá solo tres veces más, cuestión que nos insinúa que el problema de Picasso se desliza fuera de la cuestión de la alegoría de la representación. Lo mismo podemos decir respecto del espejo: si en Velázquez la oscuridad de las ventanas y los cuadros contrasta con el espejo, aquí la claridad de las ventanas y de la puerta del fondo contrastarán con un espejo que mantiene siempre un lugar secundario, si no es que directamente no lo encontramos.

Evidentemente, la silueta de Nieto es el centro de atención. A lo largo de la serie la centralidad del personaje se hace cada vez más imponente, hasta constituir un verdadero agujero al que la escena general parece caer. (Cf. MPB 70463; MPB 70465; y MPB 70466). Susan G. Galassi llama la atención en su análisis de la serie respecto de las variaciones y la función de la variación de este personaje:

El avatar de Nieto se ha transformado desde que apareció por primera vez en la serie: ahora es una figura más grande, más fiel a la pose de su prototipo con el brazo extendido, pero también puede sugerir la del artista delante del caballete; de hecho, es una pose que recuerda a un artista concretamente. Como señala Juan Marín, esta figura evoca a Goya en su famoso autorretrato con traje de torero de la Real Academia de San Fernando en Madrid [...]. De hecho, a medida que Picasso avanzó en su interpretación de la obra de Velázquez, Goya fue presentándose como integrante de su particular lectura del origen de Las Meninas (2008: 96).

Esta incorporación de Goya creemos que sucede en dos sentidos: por un lado la inserción del problema de la serie. Las series de grabados de Goya implican un antecedente que quizás habilite una lectura de la serie en Picasso. Pero también es la inserción de un tercero entre Velázquez y Picasso: un tercer pintor que triangula la representación: le quita el lugar a Velázquez, pinta desde el fondo, y desde ese fondo hace pasar la imagen por el punto de fuga. El espejo es relegado en la representación, pero la operación de transfiguración que el espejo representa reaparece en el pintor. Como si en una lectura atenta de Platón, se invirtiera su condena de la pintura en República: claro que el pintor y el espejo ocupan un lugar análogo, en tanto creadores de realidad por fuera de la estructura representativa de la idea. Este gesto puede ser leído en términos de paso a la presentación: no ya el problema de la re-presentación, sino el acto de creación absoluta del pintor. 
Un segundo personaje que se ubica en los bordes, es el del bufón. Picasso recurre a un método muy simple para señalarlo: lo deja sólo esbozado y sin pintar. El personaje tendrá su propia mutación. Si Nieto parece convertirse en un nuevo pintor en el interior del cuadro, Nicolasito Pertusato sufre una transformación similar: su gesto de equilibrio con las manos levantadas a la altura del pecho se convierte en el gesto del pianista sobre su instrumento (MP 70472). No es menor que en una serie que requiere para su experiencia de una temporalidad diferente a la del cuadro tradicional, se incorpore un músico a la escena. Es además la imagen del pianista acompañante, aquel que se mantiene en el margen para dejar que otro personaje principal, el solista, juegue su papel. Esta escenificación se acentúa si ponemos en diálogo este lienzo con el último de la serie en el que Isabel de Velasco parece saludar al público, porque nos encontramos con una clara referencia a la teatralidad y un despliegue temporal de la serie. Si el teatro musical de la época recuperaba los gestos del concierto tradicional para componer con ellos un nuevo código musical, también Picasso aquí parece extraer los gestos teatrales del cuadro.

Hacíamos referencia en el inicio a la necesidad de pensar qué sería una transvaloración de lo verdadero y lo falso. Tambien sugeríamos que Picasso parecia seguir una lógica pre-clásica, anterior al problema de la representación en términos modernos o una lógica que dependería antes que de la distancia entre verdad y falsedad de la potencia de lo falso. La frase de Nietzsche no implica un mero relativismo de los juicios, sino más bien la conversión del juicio en la expresión de un afecto: "No debemos preguntarnos: "¿quién interpreta pues?», al contrario, el interpretar mismo, corno una forma de la voluntad de poder, tiene existencia (pero no como un «ser», sino como un proceso, un devenir) como una afección” (1998: 34-35). Evidentemente, es esto lo que a Picasso ocupa, pintar los afectos que los cuerpos expresan, más allá de cualquier utopía vanguardista y más allá de toda semiótica postestructuralista. Lo único que quedan son los cuerpos y sus fuerzas. "Pintar las fuerzas", aquello que Deleuze admiraba en la obra de Bacon, parece aquí ya elaborado por su maestro.

\section{REFERENCIAS:}

Las obras pertenecientes a la serie Las meninas según Velázquez de Picasso, se citan siguiendo la numeración de catálogo del Museu Picasso de Barcelona. (p.e. MP 70492)

Berger, John. (1973). Ascensión y caída de Picasso. Trad. y prólogo de Manuel de la Escalera. Madrid: Akal.

Deleuze, Gilles. (1986). La imagen-tiempo. Estudios sobre cine 2. Trad. de Irene Agoff. Barcelona: Paidós.

Deleuze, Gilles y Félix Guattari. (1988). Mil Mesetas. Capitalismo y esquizofrenia. Trad. José Vázquez Pérez. Valencia: Pre-Textos.

Derrida, Jacques. (1989). "La retirada de la metáfora". En La deconstrucción en las

fronteras de la filosofía. Trad. de Patricio Peñalver. Barcelona: Paidós.

Galassi, Susan G. (2008). "Rito de paso: el viaje de Picasso por Las Meninas". En Olvidando a Velázquez. Las Meninas. Barcelona: Museo Picasso [Catálogo de exposición].

Krauss, Rosalind E. (1999). Los papeles de Picasso. Trad. Mireya Reilly de Fayard. Barcelona: Gedisa.
Lubar, Robert S. (2008). "Picasso, Las Meninas y el advenimiento del cubismo". En Olvidando a Velázquez. Las meninas.ob. cit.

Marias, Fernando [comp.]. (2007). Otras Meninas. Madrid: Siruela.

Nietszche, Friedrich. (1998). El nihilismo. Escritos póstumos. Selección y trad. de Gonçal Mayos. Barcelona: Península.

Rafart, Claustre. (1999). Las Meninas de Picasso. La dialéctica como instrumento de comunicación artística. Apuntes. En Kalias. Revista de Arte. IVAM Centre Julio González, Generalitat Valenciana.

Saxl, Fritz. (1989). La vida de las imágenes. Estudios iconográficos sobre el arte occidental. Madrid: Alianza.

Searle, John. (1980). Las Meninas and the paradoxes of pictorial representation. Critical Inquiry 3: 477-488.

Snyder, Joel y Ted Cohen. (1980). Reflexions on Las Meninas: Paradox lost. Critical Inquiry 9: 429-447.

Steinberg, Leo. (1981). Velázquez Las Meninas. October, vol. 19: 45-54.

Recepción: lunes 26 de octubre de 2009 Aceptación: martes 19 de enero de 2010 